\title{
Biomassa residual do processamento de produtos hortícolas da Amazônia para crescimento micelial e produção de proteases por uma espécie de cogumelo comestível
}

\author{
Residual biomass from Amazon's horticultural residues processing for mycelial growth and \\ production of proteases by an edible mushroom species \\ Biomasa residual del procesamiento de productos hortícolas de la Amazonia para crecimiento \\ micelial y producción de proteasas por una especie de hongo comestible
}

Recebido: 27/02/2021 | Revisado: 05/03/2021 | Aceito: 10/03/2021 | Publicado: 18/03/2021

\author{
Samara Claudia Picanço Batista \\ ORCID: https://orcid.org/0000-0002-7430-6104 \\ Universidade Federal do Amazonas, Brasil \\ E-mail: samara.claudia18@gmail.com \\ Fabiano Brito Prado \\ ORCID: https://orcid.org/0000-0002-1334-1424 \\ Universidade Federal do Amazonas, Brasil \\ E-mail: fabiano.prado7@gmail.com \\ Ana Kezia Pimentel de Brito \\ ORCID: https://orcid.org/0000-0001-7925-4908 \\ Universidade Federal do Amazonas, Brasil \\ E-mail: anakeziapimentel@gmail.com \\ Maria do Perpétuo Socorro de Lima Verde Coelho \\ ORCID: https://orcid.org/0000-0002-0626-3456 \\ Universidade Federal do Amazonas, Brasil \\ E-mail:1vcoelho1@gmail.com \\ Teresa Alarcón Castillo \\ ORCID: https://orcid.org/0000-0002-3107-1704 \\ Universidad Nacional Intercultural de la Amazonia, Peru \\ E-mail: talarconc@unia.edu.pe \\ Salomão Rocha Martim \\ ORCID: https://orcid.org/0000-0003-0789-2411 \\ Universidade Nilton Lins, Brasil \\ E-mail: salomao.martim@gmail.com \\ Maria Francisca Simas Teixeira \\ ORCID: https://orcid.org/0000-0002-9703-1932 \\ Universidade Federal do Amazonas, Brasil \\ E-mail: mteixeira@ufam.edu.br
}

\begin{abstract}
Resumo
Resíduos hortícolas podem ser utilizados para a cultivo de cogumelos e obtenção de proteases. O objetivo desta pesquisa foi avaliar o potencial de resíduos lignocelulósicos como substratos para o crescimento micelial e produção de proteases por Lentinus crinitus DPUA 1693. A cultura matriz foi preparada em ágar batata dextrose (BDA) suplementada com extrato de levedura (YE) $0,5 \%(\mathrm{p} / \mathrm{v})$. O crescimento micelial vertical (VMC) foi realizado em tubos de ensaio contendo os seguintes resíduos lignocelulósicos suplementados com farelo de arroz (FA): serragem, (SER), semente de açaí (SA) e exocarpos de abacaxi (CAB), cupuaçu (CC) e tucumã (CT). O vigor micelial foi classificado pelo método subjetivo de notas em: Fracamente adensado (I), Mediamente adensado (II) e Fortemente adensado (III). A atividade proteolítica foi determinada utilizando solução de azocaseína $1 \%(\mathrm{p} / \mathrm{v})$. A caracterização enzimática foi realizada no extrato obtido do cultivo de L crinitus no resíduo lignocelulósico que favoreceu o desenvolvimento de micélio fortemente adensado e produção significativa de proteases. A VMC significativa foi determinada em SER+FA $(0,40 \mathrm{~cm} / \mathrm{dia})$. Em CC+FA, este cogumelo cresceu e formou micélio fortemente adensado (III). Atividade proteolítica significativa foi determinada nos cultivos de $L$. crinitus em CC+FA $(6,71 \mathrm{U} / \mathrm{mL})$ e CT+FA $(6,44 \mathrm{U} / \mathrm{mL})$. No extrato bruto de $L$. crinitus cultivado em $\mathrm{CC}+\mathrm{FA}$ houve predomínio de aspártico proteases que demonstraram atividade ótima em pH 5 , a $50{ }^{\circ} \mathrm{C}$. Essas enzimas foram fortemente inibidas por $\mathrm{Zn}^{+2}$ e $\mathrm{Mn}^{+2}$. Os resíduos lignocelulósicos utilizados favorecem a produção de massa micelial e proteases por L. crinitus.
\end{abstract}

Palavras-chave: Cupuaçu; Exocarpo; Hidrolases; Lentinus crinitus; Resíduos lignocelulósicos. 


\begin{abstract}
Horticultural residues can be used for growing mushrooms and obtaining proteolytic enzymes. The objective of this research was to evaluate the potential of lignocellulosic residues as substrates for mycelial growth and production of proteases by Lentinus crinitus. The matrix culture was prepared on potato dextrose agar (BDA) supplemented with yeast extract (YE) $0.5 \%(\mathrm{w} / \mathrm{v})$. Vertical mycelial growth (VMC) was carried out in test tubes containing the following lignocellulosic residues supplemented with rice bran (FA): sawdust, (SER), açaí seed (SA) and pineapple exocarps (CAB), cupuaçu (CC) and tucumã (CT). Mycelial vigor was classified by the subjective method of notes. Proteolytic activity was determined using $1 \%(\mathrm{w} / \mathrm{v})$ azocasein solution. The enzymatic characterization was carried out in the extract obtained from the cultivation of $L$. crinitus in the mixture of residues that favored the development of highly densified mycelium and significant production of proteases. Significant VMC was determined in SER+FA $(0.40 \mathrm{~cm} / \mathrm{day})$. In CC+FA, $L$. crinitus developed a strongly densified mycelium. Significant proteolytic activity was determined in CC+FA $(6.71 \mathrm{U} / \mathrm{mL})$ and $\mathrm{CT}+\mathrm{FA}(6.44 \mathrm{U} / \mathrm{mL})$ cultures. In the extract of the culture in CC+FA there was a predominance of aspartic proteases that demonstrated an optimal activity at $\mathrm{pH} 5$, at $50^{\circ} \mathrm{C}$. These enzymes were strongly inhibited by $\mathrm{Zn}^{+2}$ and $\mathrm{Mn}^{+2}$. Residues from Amazonian horticulture used favor the production of mycelial mass and proteases by $L$. crinitus.
\end{abstract}

Keywords: Cupuaçu; Exocarp; Hydrolases; Lentinus crinitus; Lignocellulosic residues.

\title{
Resumen
}

Los residuos hortícolas se pueden utilizar para cultivar setas y obtener enzimas proteolíticas. El objetivo de esta investigación fue evaluar el potencial de los residuos lignocelulósicos como sustratos para el crecimiento micelial y la producción de proteasas por Lentinus crinitus. El cultivo de la matriz se realizó en agar papa dextrosa (APD) suplementado con extracto de levadura (EL) $0.5 \%(\mathrm{p} / \mathrm{v})$. El crecimiento micelial vertical (CMV) se ejecutó en tubos de ensayo que contenían los siguientes residuos lignocelulósicos suplementados con salvado de arroz (SA): aserrín (A), semilla de asaí (SA) y exocarpos de piña (CP), copoazú (CC) y tucumá (CT). El vigor micelial estuvo clasificado por el método subjetivo de notas y la actividad proteolítica fue determinada usando una solución de azocaseína 1\% (p/v). Asimismo, la caracterización enzimática se realizó usando el extracto obtenido de la mezcla de residuos que favorecieron el buen desarrollo micelial de L. crinitus y su producción de proteasas. Los resultados indicaron un CMV significativo en $\mathrm{A}+\mathrm{SA}(0.40 \mathrm{~cm} /$ día $)$ mientras que en $\mathrm{CC}+\mathrm{SA}$ el micelio de L. crinitus se desenvolvió muy vigorosamente. Los cultivos en $\mathrm{CC}+\mathrm{SA}(6.71 \mathrm{U} / \mathrm{mL})$ y $\mathrm{CT}+\mathrm{SA}(6.44 \mathrm{U} / \mathrm{mL})$ fueron los que expresaron mejor actividad proteolítica, siendo que el extracto obtenido del cultivo en $\mathrm{CC}+\mathrm{SA}$ tuvo predominancia de proteasas aspárticas con optima actividad en pH 5 y a $50{ }^{\circ} \mathrm{C}$, las cuales estuvieron fuertemente inhibidas por $\mathrm{Zn}^{+2}$ y $\mathrm{Mn}^{+2}$. Se concluye que los residuos de la horticultura amazonica estimulan la producción de masa micelial y proteasas por L. crinitus.

Palabras clave: Copoazú, Exocarpo, Hidrolasas; Lentinus crinitus; Residuos lignocelulósicos.

\section{Introdução}

Proteases são hidrolases que atuam na clivagem de proteínas em peptídeos e aminoácidos. Na área comercial, as enzimas proteolíticas continuam predominando e atualmente representam 65\% do total de venda mundial (Barzkar, Homaei, Hemmati, \& Patel, 2018; Justina, Justina, \& Skoronsk, 2018). O mercado global de proteases foi estimado em US\$2,21 bilhões em 2021, com perspectivas de crescimento contínuo nos anos subsequentes (Rohan, 2021).

As enzimas proteolíticas disponíveis atualmente não suprem à crescente demanda comercial, condição que incentiva a busca constante por novas fontes naturais e renováveis desses biocatalisadores (Madhusankha \& Thilakarathna, 2021). Neste contexto, os cogumelos comestíveis vêm se destacando como produtores significativos de proteases com características bioquímicas favoráveis para uso em diversas aplicações biotecnológicas e comerciais (Machado, Teixeira, Kirsch, Campelo, \& Oliveira, 2016; Martim et al., 2017).

A fermentação em estado sólido (FES) é um processo ecoamigável e de baixo custo, pois são utilizadas baixas quantidades de água e energia no cultivo de cogumelos (Machado et al., 2016). A utilização de resíduos lignocelulósicos como madeira, sementes e exocarpos para a obtenção de proteases é outra vantagem tecnológica da FES, pois são desenvolvidos bioprocessos estáveis, seguros e com elevada produção enzimática (Boratyński, Szczepańska, Grudniewska, Gniłka, \& Olejniczak, 2018; Verduzco-Oliva \& Gutierrez-Uribe 2020).

As características vantajosas da FES estão relacionadas às propriedades nutricionais dos resíduos lignocelulósicos. Estas matérias primas vegetais geralmente são constituídas por carboidratos, proteínas, lipídios e minerais que além de favorecer o 
crescimento micelial, também estimulam a síntese de compostos bioativos como as proteases, por diversas espécies de cogumelos comestíveis (Inácio et al., 2015; Ravindran, Hassan, Williams, \& Jaiswal, 2018; Brito, Braga, Teixeira, \& Martim, 2019).

$\mathrm{Na}$ Amazônia brasileira, as biomassas de espécies vegetais vêm sendo utilizadas como substratos na FES. Resíduos obtidos do processamento de abacaxi (Ananas comosus), açaí (Euterpe oleracea Mart.), arroz (Oryza sativa) e cupuaçu (Theobroma grandiflorum (Willd. ex Spreng.) Schum.) foram citados como substratos eficientes para produção de biomassa e enzimas proteolíticas por diferentes espécies de cogumelos comestíveis pertencentes aos gêneros Pleurotus e Lentinus (Fonseca, Barroncas, \& Teixeira, 2014; Souza et al., 2016).

Entre os cogumelos, Lentinus crinitus (L.) Fr., espécie pertencente à família Polyporaceae, filo Basidiomycota, vem se destacando como uma fonte promissora para a obtenção de proteases por fermentação submersa (Magalhães et al., 2019). Entretanto, há poucos relatos do cultivo e produção de enzimas proteolíticas por L. crinitus cultivado em FES. O objetivo deste estudo foi avaliar resíduos lignocelulósicos da fruticultura amazônica como substratos para o crescimento micelial e produção de proteases por L. crinitus DPUA 1693.

\section{Metodologia}

\subsection{Cogumelo}

Nesta pesquisa foi utilizado Lentinus crinitus DPUA 1693, espécie cedida pela Coleção de Culturas DPUA, da Universidade Federal do Amazonas-UFAM. Para obtenção de cultura viável da forma micelial, L. crinitus foi inoculado em ágar Batata Dextrose (BDA) suplementado com extrato de levedura (YE) 0,5\% (p/v). Os cultivos foram mantidos na ausência de luz, a $25^{\circ} \mathrm{C}$ (Fonseca et al., 2014). Após oito dias, essas os culturas foram usadas como inóculo para avaliação do crescimento micelial vertical e produção de proteases por $L$. crinitus.

\subsection{Seleção de resíduos lignocelulósicos para crescimento micelial vertical e síntese de proteases por $L$. crinitus}

\subsubsection{Obtenção dos Resíduos Lignocelulósicos}

Para avaliar o crescimento de L. crinitus foram utilizados, farelo de arroz (FA) serragem (SER), semente de açaí (SA) e exocarpos de abacaxi (CAB), cupuaçu (CC) e tucumã (CT) (Astrocaryum aculeatum G. Mey), obtidos de produtores locais na cidade de Manaus e no distrito de Novo Remanso (Itacoatiara-AM).

\subsubsection{Tratamento dos Resíduos Lignocelulósicos}

Os resíduos lignocelulósicos foram lavados em água corrente e higienizados com solução desinfetante para hortifrutícolas contendo cloro ativo $0,85 \%$. Após 15 minutos foram submetidos à lavagem sucessiva, seguindo a drenagem do excesso de líquido. Em seguida, cada resíduo foi suplementado com FA, na proporção de 80:20 (p/p), a umidade e o pH aferidos para $60 \%$ e 6,0, respectivamente. Os substratos foram acondicionados em tubos de ensaio (200 $\mathrm{mm} \times 25 \mathrm{~mm}$ ) contendo na sua base algodão umedecido com água destilada, formando uma coluna de $15 \mathrm{~cm}$. Estes tubos contendo as misturas de resíduos foram esterilizados a $121^{\circ} \mathrm{C}$, durante 60 minutos, por três dias consecutivos, procedendo ao resfriamento por 24 horas. Na parte externa de cada tubo foram afixadas três fitas milimetradas $(130 \mathrm{~mm}$ x $10 \mathrm{~mm}$ ) (Palheta, Vieira, Neves, \& Teixeira, 2011; Fonseca et al., 2014).

\subsubsection{Avaliação do crescimento micelial vertical de $L$. crinitus}

Para avaliar a velocidade do crescimento micelial vertical (VMC) três discos medindo $8 \mathrm{~mm}$ de diâmetro foram inoculados na superfície de cada mistura de resíduos e o bioprocesso foi conduzido a $25{ }^{\circ} \mathrm{C}$, na ausência de luz. A VMC foi determinada a cada 24 horas durante 15 dias, conforme a descrito na Equação 1 . O vigor micelial foi classificado pelo método 
subjetivo de notas em: Fracamente adensado (I), Mediamente adensado (II) e Fortemente adensado (III) (Fonseca et al., 2014; Machado, Martim, Alecrim, \& Teixeira, 2017).

$$
\text { Equação 1: } \mathrm{VMC}=\frac{\text { wf- wi }}{\text { tf }}
$$

Onde: $\mathrm{vf}=$ crescimento final; $\mathrm{vi}=$ crescimento inicial $\mathrm{e}, \mathrm{tf}=$ tempo final.

\subsubsection{Extração das proteases sintetizadas por L. crinitus cultivados em resíduos lignocelulósicos}

As proteases foram extraídas em água destilada esterilizada na razão 5:1 (água: resíduo lignocelulósico, v/p) sob agitação (180 rpm), a $25^{\circ} \mathrm{C}$. Após 30 minutos, o extrato bruto foi recuperado por filtração em tecido de musseline, posteriormente filtrado a vácuo, seguido de centrifugação ( 8.000 x g/5 minutos). Em seguida, o extrato foi filtrado usando a membrana polietersulfônica $0,22 \mu$. Após obtenção do extrato foram realizados os estudos de determinação de atividade proteásica e caracterização enzimática (Fonseca et al., 2014).

\subsubsection{Determinação da atividade proteolítica}

A atividade proteolítica foi determinada de acordo com a metodologia descrita por Leighton, Doi, Warren e Kelln (1973), utilizando como substrato solução de azocaseína 1\% (p/v), em tampão Tris-HCl pH 7,2. Uma unidade de atividade de proteases foi definida como a quantidade de enzima necessária para produzir variação de absorbância igual a 0,1 durante 60 minutos, a $440 \mathrm{~nm}$.

\subsection{Caracterização bioquímica das proteases de $L$. crinitus}

Para os testes de caracterização enzimática foi utilizado o extrato obtido do cultivo de L. crinitus no resíduo lignocelulósico que favoreceu o desenvolvimento de micélio fortemente adensado e produção significativa de proteases.

\subsubsection{Efeito do pH na atividade e estabilidade proteolítica}

Para avaliar o pH ótimo, a atividade proteolítica foi determinada em $25^{\circ} \mathrm{C}$, utilizando as seguintes soluções tampão a 0,1 M: acetato de sódio (pH 5 e 6), Tris- $\mathrm{HCl}$ ( $\mathrm{pH} 7$ e 8) e Glicina- $\mathrm{NaOH}$ (pH 9 e 10), durante uma hora. Na avaliação da estabilidade ao $\mathrm{pH}$, o extrato enzimático foi diluído em cada tampão (1:1, v/v), a $25^{\circ} \mathrm{C}$, por uma hora (Martim et al., 2017).

\subsubsection{Efeito da temperatura na atividade e estabilidade proteolítica}

Para determinar o efeito da temperatura na atividade proteolítica, o extrato enzimático e a solução de azocaseína foram incubados na faixa de $30^{\circ} \mathrm{C}$ a $80^{\circ} \mathrm{C}$, durante uma hora. No ensaio de estabilidade à temperatura, os extratos foram incubados em temperaturas de 30 a $80{ }^{\circ} \mathrm{C}$, por uma hora. Em seguida esses extratos foram misturados com solução de azocaseína, procedendo à quantificação da atividade enzimática. Os resultados foram expressos em atividade relativa em todos os experimentos (Martim et al., 2017).

\subsubsection{Efeito de íons metálicos e inibidores na atividade enzimática}

O efeito de inibidores na atividade proteolítica foi determinado pela incubação do extrato enzimático com as seguintes substâncias 1mM: ácido etilenodiamino tetra-acético (EDTA), ácido iodoacético, fluoreto de fenilmetilsulfonila (PMSF) e pepstatina. Na análise do efeito dos íons metálicos na ação catalítica das proteases foram utilizadas as soluções 1 mM: sulfato ferroso (FeSO4), sulfato de manganês (MnSO4), sulfato de magnésio (MgSO4), cloreto de sódio ( $\mathrm{NaCl}$ ), sulfato de zinco 
( $\mathrm{ZnSO} 4)$, cloreto de potássio $(\mathrm{KCl})$, cloreto de cálcio $(\mathrm{CaCl} 2)$ e sulfato de cobre $(\mathrm{CuSO} 4)$. As misturas reacionais foram incubadas nas condições ótimas de $\mathrm{pH}$ e de temperatura. A atividade enzimática residual foi comparada com o controle, incubado sem os inibidores ou íons metálicos e correspondeu a $100 \%$ de atividade (Martim et al., 2017).

\subsection{Análise estatística}

Em todos os experimentos realizados em triplicata, os dados foram submetidos à análise estatística de variância e as médias foram comparadas pelo teste de Tukey $(\rho<0,05)$, usando o programa Minitab, versão 18.1 (Minitab, 2017).

\section{Resultados e Discussão}

\subsection{Crescimento micelial vertical de $L$. crinitus em resíduos lignocelulósicos}

A tabela 1 demonstra a velocidade do crescimento micelial vertical (VMC) e as características do vigor micelial de $L$. crinitus cultivado em diferentes resíduos lignocelulósicos. Nas condições avaliadas foi verificado que a VMC variou de acordo com a mistura de substratos utilizada. A VMC significativa foi determinada em SER+FA (0,40 cm/dia). Em CC+FA, CT+FA e SA+FA a VMC foi 30\%, 60\% e 75\% inferior, quando comparada com os resultados obtidos em SER+FA. Não houve crescimento micelial de L. crinitus em CAB+FA. Macedo, Kirsch, Palheta, Putzke e Teixeira (2011) e Fonseca, Silva, Alecrim, Cruz e Teixeira (2015) relataram VMC de $0,70 \mathrm{~cm} /$ dia e $0,41 \mathrm{~cm} /$ dia para Ganoderma lucidum e $P$. ostreatoroseus cultivados em SER+FA e SA+CAB, respectivamente. Neves (2012) citou que CC+liteira favoreceu o desenvolvimento micelial de $P$. ostreatus e P. florida. O crescimento micelial de cogumelos é influenciado por fatores genéticos, composição nutricional do substrato, $\mathrm{pH}$ do meio de cultivo, temperatura, umidade ambiental, concentrações de $\mathrm{CO}_{2}$, relação carbono/nitrogênio e tamanho das partículas do (Palheta et al., 2011; Bellettini et al., 2019).

Tabela 1. Crescimento e vigor micelial de $L$. crinitus cultivado em resíduos lignocelulósicos.

\begin{tabular}{lcc}
\hline Resíduos agroindustriais & Média VMC $(\mathbf{c m} /$ dia) & Vigor \\
\hline SER+FA & $0,40 \pm 0,01^{\mathrm{a}}$ & Fracamente adensado (I) \\
CC+FA & $0,28 \pm 0,04^{\mathrm{b}}$ & Fortemente adensado(III) \\
CT+FA & $0,16 \pm 0,05^{\mathrm{c}}$ & Mediamente densado(II) \\
SA+FA & $0,10 \pm 0,01^{\mathrm{d}}$ & Fracamente adensado(I) \\
CAB+FA & $\mathrm{ND}$ & ND \\
\hline
\end{tabular}

CAB+FA (exocarpo de abacaxi + farelo de arroz); SA+FA (semente de açaí + farelo de arroz); CC+FA (exocarpo de cupuaçu + farelo de arroz); CT+FA (exocarpo de tucumã + farelo de arroz); SER+FA (serragem + farelo de arroz). ND= não determinado. Letras iguais na coluna não diferem estatisticamente pelo Teste de Tukey $(\rho<0.05)$.

Fonte: Autores.

A Figura 1 demonstra a velocidade e a densidade do micélio com base no vigor micelial. Nas condições avaliadas, $L$. crinitus apresentou diferentes níveis de adensamento micelial. Em $\mathrm{CC}+\mathrm{FA}$, este cogumelo cresceu e formou micélio fortemente adensado (III). Em CT+FA, foi verificado desenvolvimento micelial mediamente adensado, enquanto que em SER+FA e SA+FA o vigor micelial foi classificado como fracamente adensado. Machado et al. (2016) observaram vigor fortemente adensado ao avaliarem o crescimento de L. citrinus em CC+FA e CC+liteira. Macedo et al. (2011) e Fonseca et al. (2015) também verificaram que a mistura $\mathrm{CC}+\mathrm{FA}$ favoreceu o crescimento e a formação de micélio fortemente adensado de G. lucidum e P. ostreatoroseus, respectivamente. O vigor micelial é influenciado pelo aumento de carboidratos, aminoácidos e minerais fornecidos pelo substrato suplementado. Além disso, inóculos com elevado vigor micelial melhoram a produção, qualidade, sabor e a vida de prateleira de cogumelos (Palheta et al., 2011; Lu, Bau, \& Ohga, 2017). 
Figura 1: Crescimento micelial de L. crinitus cultivado em resíduos lignocelulósicos.

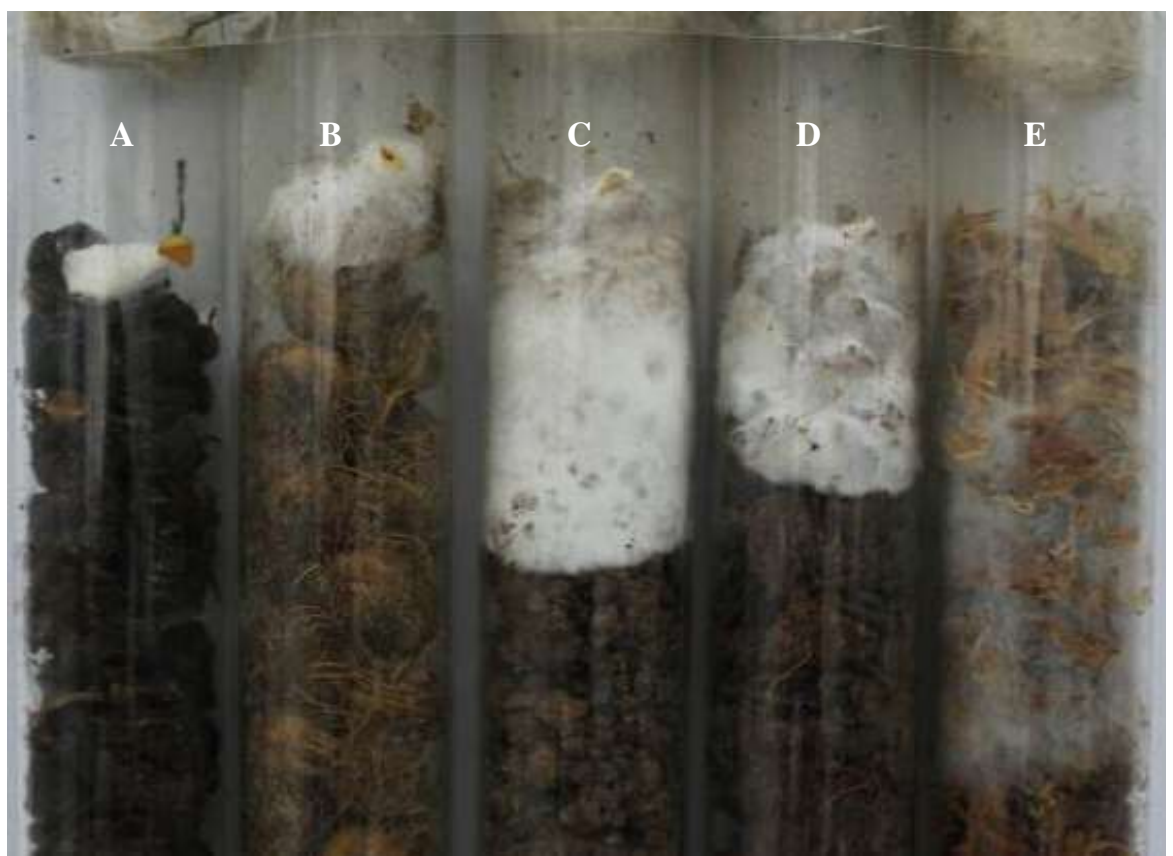

$\mathrm{A}=\mathrm{CAB}+\mathrm{FA}$ (exocarpo de abacaxi + farelo de arroz); $\mathrm{B}=\mathrm{SA}+\mathrm{FA}$ (semente de açaí + farelo de arroz); $\mathrm{C}=\mathrm{CC}+\mathrm{FA}($ exocarpo de cupuaçu + farelo de arroz); $\mathrm{D}=\mathrm{CT}+\mathrm{FA}$ (exocarpo de tucumã + farelo de arroz); $\mathrm{E}=\mathrm{SER}+\mathrm{FA}$ (serragem + farelo de arroz).

Fonte: Autores.

\subsection{Atividade proteolítica de $L$. crinitus}

No presente estudo, atividade proteolítica significativa foi determinada nos cultivos de L. crinitus em CC+FA (6,71 $\mathrm{U} / \mathrm{mL})$ e $\mathrm{CT}+\mathrm{FA}(6,44 \mathrm{U} / \mathrm{mL})$. Em SER+FA e CAÇ+FA as atividades foram 51,71\% e 80,92\% inferiores quando comparadas aos cultivos em CC+FA (Tabela 2). Resultado similar foi reportado por Machado et al. (2016) ao avaliar a produção de proteases por L. citrinus em CC+FA e CC+liteira. Fonseca et al. (2014) também verificaram produção significativa de proteases (4,50 $\mathrm{U} / \mathrm{mL}$ ) por P. ostreatoroseus cultivado em CC+FA. Brito et al. (2019) relataram que FA+semente de tucumã são substratos que favorecem a síntese de enzimas proteolíticas por $L$. crinitus. Baseado nos resultados do vigor micelial e da produção de proteases, o extrato bruto obtido do cultivo de L. crinitus em CC+FA foi utilizado nos testes de caracterização enzimática.

Tabela 2. Atividade proteolítica de L.crinitus cultivado em resíduos lignocelulósicos.

\begin{tabular}{lc}
\hline Resíduos Lignocelulósicos & Atividade proteolítica $(\mathbf{U} / \mathbf{m L})$ \\
\hline CC+FA & $6,71 \pm 0,32^{\mathrm{a}}$ \\
CT+FA & $6,44 \pm 0,44^{\mathrm{a}}$ \\
SER+FA & $3,24 \pm 0,10^{\mathrm{b}}$ \\
SA+FA & $1,28 \pm 0,26^{\mathrm{c}}$ \\
CAB+FA & $\mathrm{ND}$ \\
\hline
\end{tabular}

CAB+FA (exocarpo de abacaxi + farelo de arroz); SA+FA (semente de açaí + farelo de arroz); CC+FA (exocarpo de cupuaçu + farelo de arroz); $\mathrm{CT}+\mathrm{FA}$ (exocarpo de tucumã + farelo de arroz); $\mathrm{SE}+\mathrm{FA}$ (serragem + farelo de arroz). $\mathrm{ND}=$ não determinado. Letras iguais na coluna não diferem estatisticamente pelo Teste de Tukey $(\rho<0.05)$.

Fonte: Autores. 


\subsection{Caracterização parcial das proteases}

\subsubsection{Efeito do pH na atividade e estabilidade proteolítica}

Entre os vários parâmetros que interferem na atividade proteolítica, a temperatura e o pH são considerados cruciais para a avaliar as condições em que a enzima atinge atividade catalítica máxima (Benerjee \& Ray, 2017). Além disso, é necessário que o biocatalisador proteolítico mantenha estabilidade em amplas faixas de $\mathrm{pH}$ e temperatura para que seja utilizado em diversos processos industriais (Aguilar \& Sato, 2018).

A Figura 2 demonstra o efeito do $\mathrm{pH}$ na atividade e na estabilidade das proteases de $L$. crinitus. Nas condições avaliadas, as enzimas proteolíticas apresentaram atividade em todas as condições analisadas, mas a ação catalítica significativa foi determinada em pH 5. Em pH 8, 9 e 10 houve redução de atividade em 38,71\%, 44,78\% e 48,85\%, respectivamente. Resultados similares foram observados por Magalhães et al. (2019) ao avaliarem as proteases de L. crinitus cultivado em meio líquido. Brito et al. (2019) e Braga, Brito, Souza, Teixeira e Martim (2020) relataram que L. citrinus e L. villosus, apresentaram atividade significativa em pH 6 e 8, respectivamente. Proteases ácidas vem sendo utilizadas na produção de ração animal, queijos, cerveja, sucos, molhos e na remoção da prata contidas em filmes de raios-X (Siala, Frikha, Mhamdi, Nasri, \& Kamoun, 2012; Tavano, Berenguer-Murcia, Secundo, \& Fernandez-Lafuente, 2018).

Figura 2. Efeito do pH na atividade (A) e na estabilidade (B) das proteases de L. crinitus.
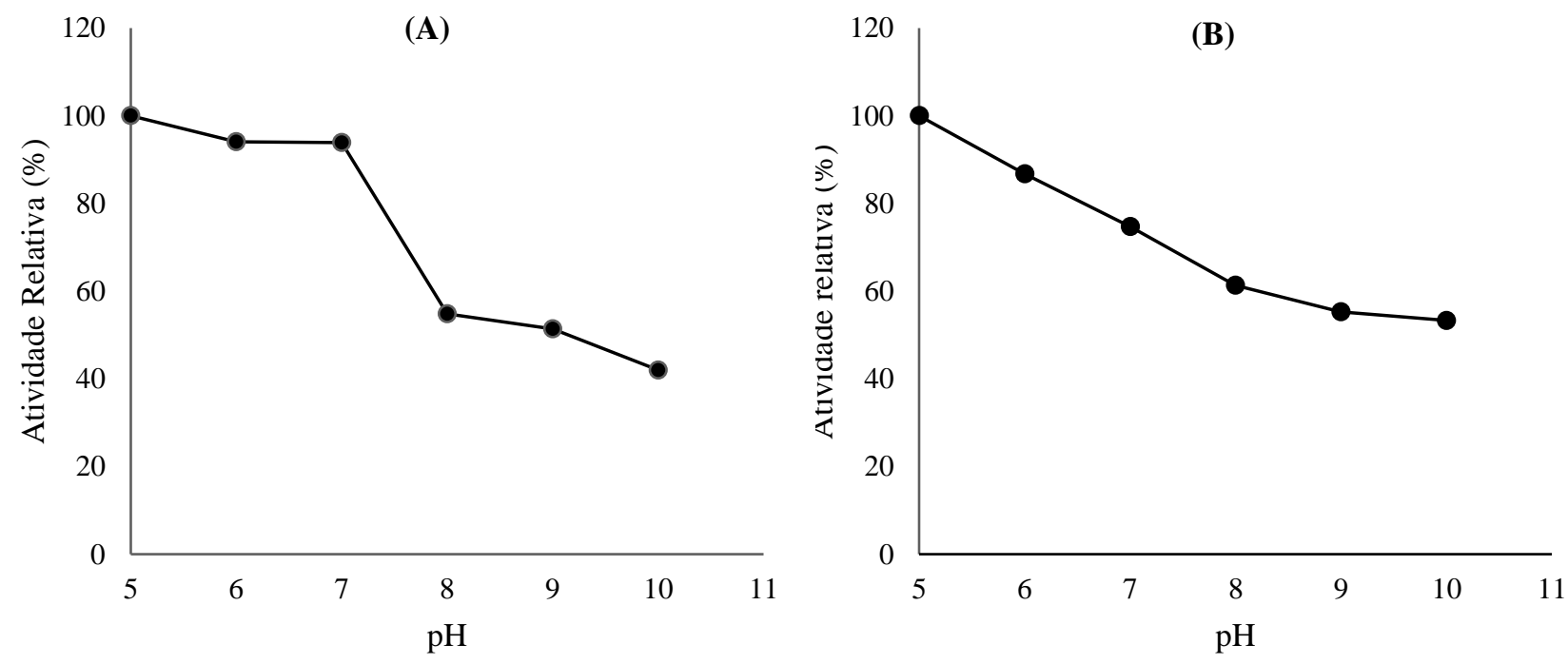

Fonte: Autores.

As proteases de L. crinitus mantiveram atividade catalítica superior a $70 \%$ na faixa de $\mathrm{pH} 5$ a 7, com redução da atividade em pH superiores. Brito et al. (2019) e Magalhães, et al. (2019) observaram que as enzimas proteolíticas de L. crinitus apresentaram resultados semelhantes, com estabilidade significativa na faixa de $\mathrm{pH} 5$ a 6. Entretanto Machado et al. (2017) relataram que proteases de L. citrinus demonstraram atividade ótima em pH 7 a 8.

\subsubsection{Efeito da temperatura na atividade e estabilidade proteolítica}

A Figura 3 mostra o efeito da temperatura na atividade e na estabilidade das enzimas proteolíticas de L. crinitus. Ação catalítica significativa foi determinada em $50{ }^{\circ} \mathrm{C}$, com declínio de atividade nas temperaturas superiores. $\mathrm{Em} 80^{\circ} \mathrm{C}$ foi verificada redução expressiva de 50,84\% de atividade proteásica. Resultados similares foram reportados por Brito et al. (2019) e Magalhães et al. (2019) ao avaliarem as características bioquímicas das proteases de L. crinitus, cultivado em matriz sólida e em meio 
líquido, respectivamente. Entretanto, Braga et al. (2020) verificaram que enzimas proteolíticas de L. villosus demonstraram atividade ótima em $60^{\circ} \mathrm{C}$.

Figura 3. Efeito da temperatura na atividade (A) e na estabilidade (B) das proteases de L. crinitus.
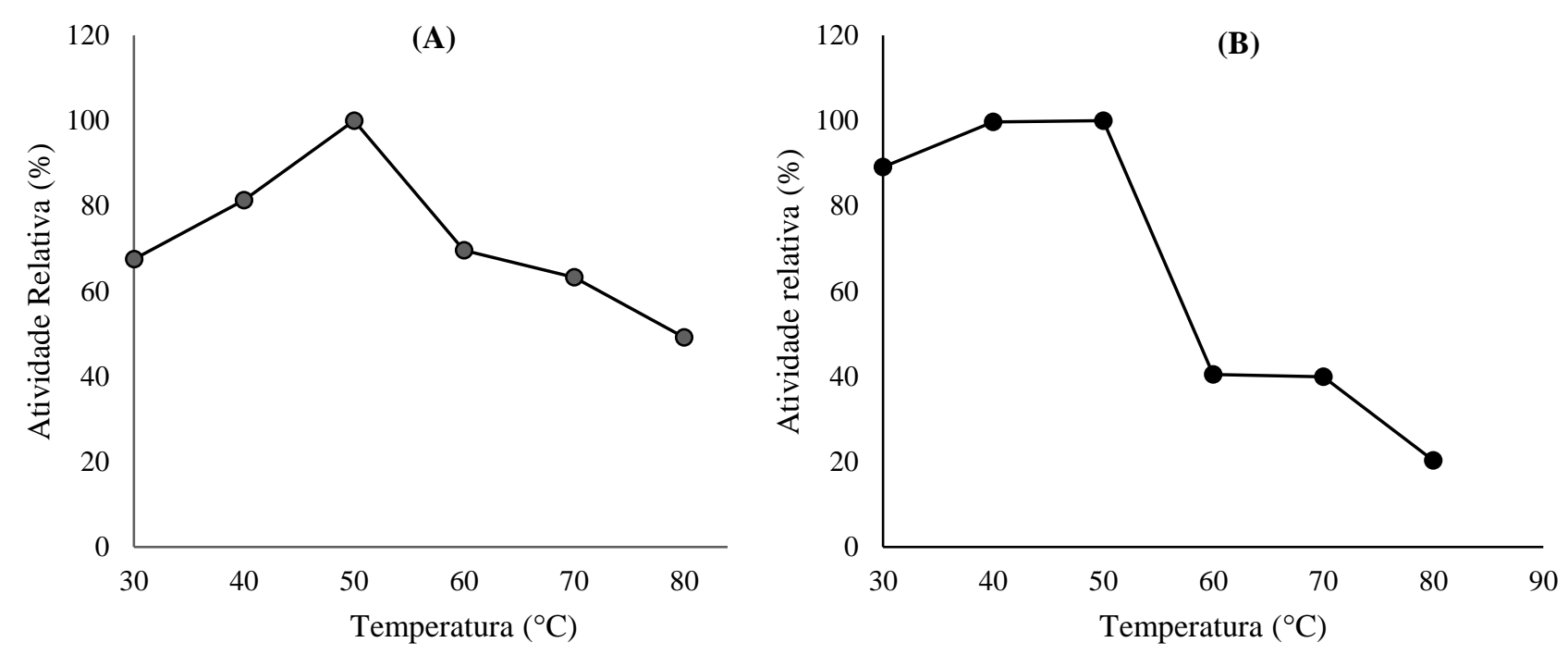

Fonte: Autores.

As proteases de L. crinitus mantiveram $100 \%$ de atividade catalítica na faixa de 40 a $50{ }^{\circ} \mathrm{C}$. Em temperaturas mais elevadas foi evidenciado decréscimo significativo de ação proteásica. Entre $60^{\circ} \mathrm{C}$ e $80^{\circ} \mathrm{C}$ foi observado declínio médio de $66,50 \%$ de atividade. Resultados similares foram reportados por Brito et al. (2019) ao caracterizarem as proteases de L. crinitus cultivado em matriz sólida. Entretanto, Magalhães et al. (2019) citaram que as proteases de L. crinitus obtidas em fermentação submersa demonstraram estabilidade entre $50^{\circ} \mathrm{C}$ a $60^{\circ} \mathrm{C}$. Braga et al. (2020) constataram que as enzimas proteolíticas de $L$. villosus mantém estabilidade na faixa de $30^{\circ} \mathrm{C}$ a $60^{\circ} \mathrm{C}$.

\subsubsection{Efeito de inibidores e de íons metálicos na atividade proteolítica}

A Figura 4 demonstra o efeito dos inibidores na atividade das enzimas proteolíticas de L. crinitus. Na presença de pepstatina, EDTA e PMSF, as proteases retiveram 30,25\%, 47,10\% e 51,30\% de atividade. Ácido iodoácetico afetou sensivelmente a ação catalítica das enzimas. Estes dados indicam a presença majoritária de aspártico proteases no extrato bruto de L. crinitus, resultado que corrobora com as citações de Brito et al. (2019). Magalhães et al. (2019) também verificaram a presença de metaloproteases e serinoproteases no extrato bruto de L. crinitus. Braga et al. (2020) classificaram as enzimas proteolíticas de L. villosus como cisteíno proteases. 
Figura 4. Efeito de inibidores na atividade proteolítica de L. crinitus.

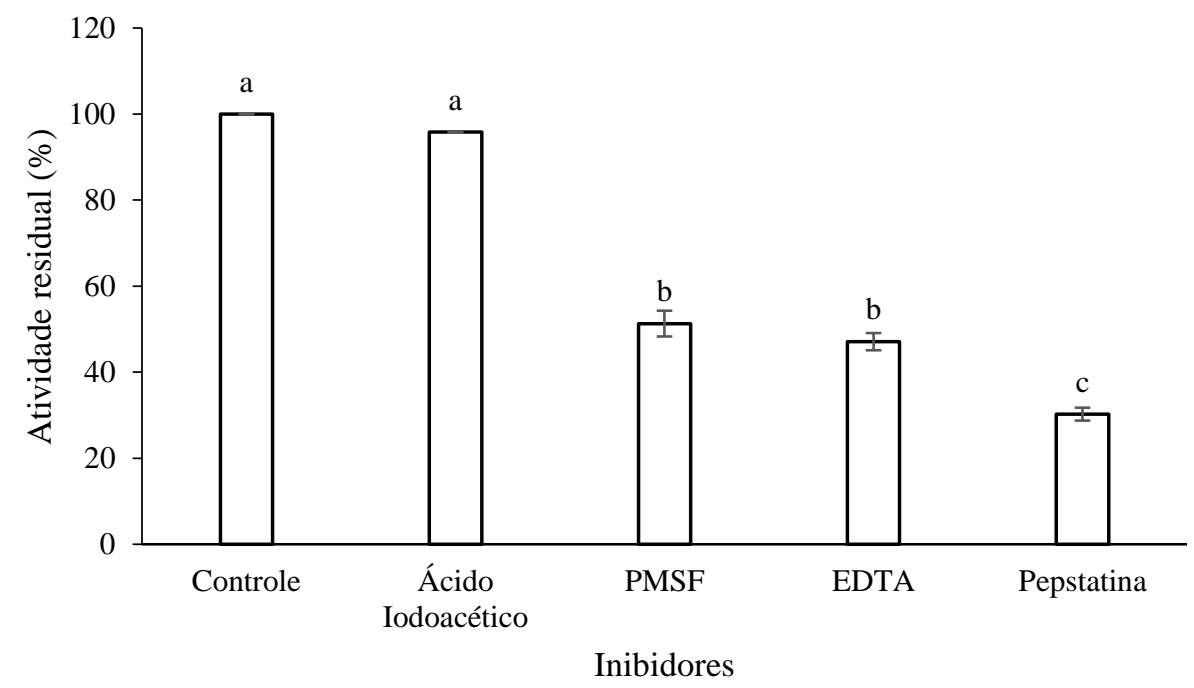

Fonte: Autores.

Nas condições avaliadas, $\mathrm{Zn}^{+2}$ e $\mathrm{Mn}^{+2}$ causaram $100 \%$ de inibição da atividade enzimática. $\mathrm{Cu}^{+2}$ reduziu em $94,9 \%$ a ação proteásica, mas na presença dos demais íons a enzima manteve atividade superior a 66\% (Figura 5). Magalhães et al. (2019) verificaram que $\mathrm{Zn}^{+2}$ reduziu em $61,71 \%$ a atividade das proteases de L. crinitus. Resultados opostos foram citados por Brito et al. (2019) e Braga et al. (2020) que constataram incremento de atividade proteolítica das enzimas de L. crinitus e L. villosus, respectivamente, na presença de $\mathrm{Mn}^{+2}$.

Figura 5. Efeito de íons metálicos atividade proteolítica de L. crinitus.

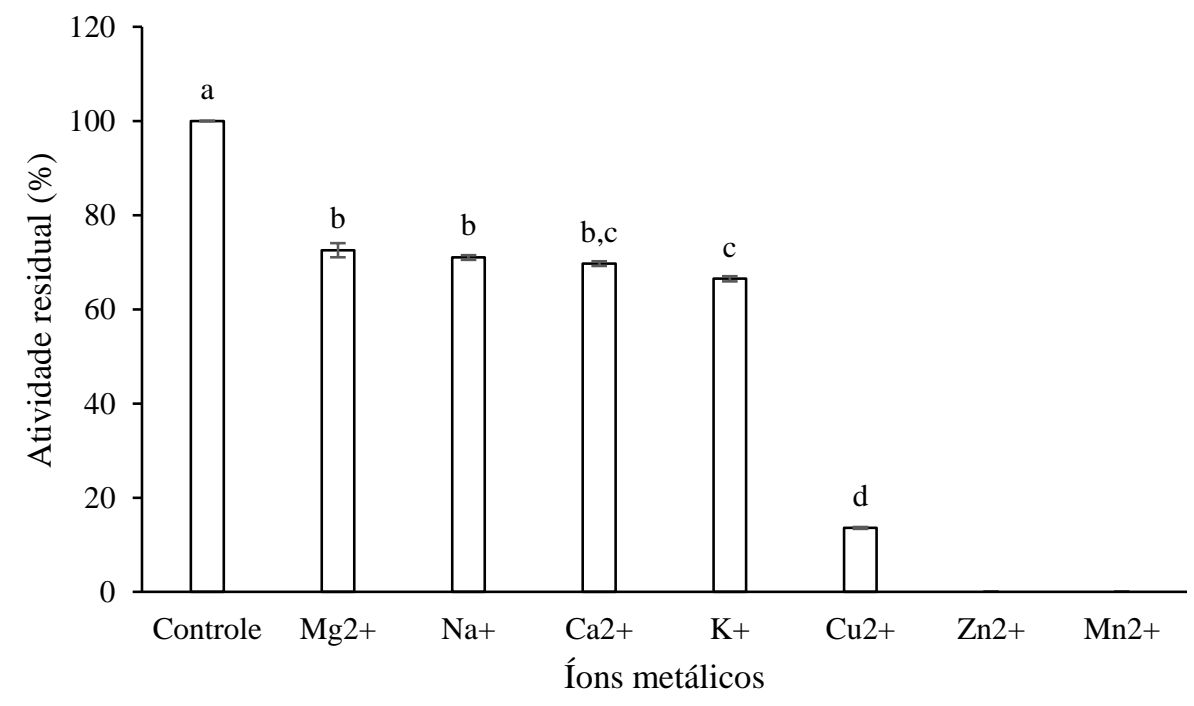

Fonte: Autores.

Os íons metálicos e as substâncias químicas atuam de forma direta ou indireta no sítio ativo da enzima, causando estímulo ou inibição da atividade catalítica (Zhao, Li, Leng, Wang, \& Li, 2013). As proteases de L. crinitus apresentaram diferentes perfis de inibição, característica bioquímica que demonstra o potencial biotecnológico desses biocatalisadores. 


\section{Conclusão}

Entre os resíduos lignocelulósicos disponíveis na floresta amazônica, exocarpo de cupuaçu suplementado com farelo de arroz $(\mathrm{CC}+\mathrm{FA})$ favorece o crescimento micelial fortemente adensado e a síntese majoritária de proteases aspárticas por Lentinus crinitus DPUA 1693 . Esses biocatalisadores possuem atividade ótima em $\mathrm{pH} 5$, a $50{ }^{\circ} \mathrm{C}$ e são fortemente inibidos por $\mathrm{Mn}^{+2} \mathrm{e} \mathrm{Zn}^{+2}$. Os resíduos do processamento de produtos vegetais da Amazônia brasileira podem ser uma alternativa sustentável para a produção de biomassa e proteases por L. crinitus.

\section{Agradecimentos}

À Fundação de Amparo à Pesquisa do Estado do Amazonas (FAPEAM) e à Universidade Federal do Amazonas (UFAM), pelo apoio técnico, científico e financeiro.

\section{Referências}

Aguilar, J. G., \& Sato, H. H. (2018). Microbial proteases: Production and application in obtaining protein hydrolysates. Food Research International, 103, 253262.

Banerjee, G., \& Ray, A. K. (2017). Impact of microbial proteases on biotechnological industries. Biotechnology and Genetic Engineering Reviews, 33(2), 119143.

Barzkar, N., Homaei A., Hemmati R., \& Patel, S. (2018) Thermostable marine microbial proteases for industrial applications: scopes and risks. Extremophiles, 22(3), 335-346

Bellettini, M. B., Fiorda, F. A., Maieves, H. A., Teixeira, G. L., Ávila, S., Hornung, P. S., Maccari Junior, A., \& Ribani, R. H. Factors affecting mushroom Pleurotus spp. (2019). Saudi Journal of Biological Sciences, 26(4), 633-646.

Boratyński, F., Szczepańska, E., Grudniewska, A., Gniłka, R., \& Olejniczak, T. (2018). Improving of hydrolases biosynthesis by solid-state fermentation of Penicillium camemberti on rapeseed cake. Scientific reports, 8(1), 1-9.

Braga, R. S. B., Brito, E. C. M., Souza, R. A. T., Teixeira, F. S., \& Martim, S. R. (2020). Lentinus villosus Klotzsch (1833) AM 169: uma fonte natural e renovável de protease alcalina. Brazilian Journal of Development, 6(11), 85867-85883.

Brito E. C. M., Braga, R. S., Teixeira, M. F. S., \& Martim, S. R. (2019). Produção e caracterização parcial de proteases aspárticas sintetizadas por Lentinus crinitus (L.) Fr. 1825 DPUA 1693 (Polyporaceae). Boletim Museu Paraense Emílio Goeldi, 14(3), 463-472.

Fonseca, T. R. B; Barroncas, J. F; \& Teixeira, M. F. S. (2014). Production in solid matrix and proteases partial characterization of edible mushroom from amazon rain forest. Revista Brasileira de Tecnologia Agroindustrial, 8 (1), 1227-1236.

Fonseca, T. R. B., Silva, T. A., Alecrim, M. M., Cruz, R. F., Filho, \& Teixeira, M. F. S. (2015). Cultivation and nutritional studies of an edible mushroom from North Brazil. African Journal of Microbiology Research, 9(30), 1814-1822.

Inácio, F. D., Ferreira, R. O., Araujo, C. A. V., Brugnari, T., Castoldi, R., Peralta, R. M., \& Souza, C. G. M. (2015). Proteases of Wood Rot Fungi with Emphasis on the Genus Pleurotus. BioMed Research International, 1-10.

Justina, M. D., Justina, M. B. D., \& Skoronsk, E. (2018). O uso das enzimas na indústria de laticínios: uma breve revisão. Revista do Instituto Laticínios Cândido Tostes, 73(3), 172-184.

Leighton. T. J., Doi, R. H., Warren, R. A. J., \& Kelln, R. A. (1973). The relationship of serine protease activity to RNA polymerase modification and sporulation in Bacillus subtilis. Journal Molucular Bioloogy, 76(1), 103-122.

Lu, T., Bau, T., \& Ohga, S. (2017). Physiological study of the wild edible mushroom Leucocalocybe mongolica. Journal- Faculty of Agriculture Kyushu University, 62(1), 1-8

Macedo, A. J. P., Kirsch, L. S., Palheta, R. A., Putzke, J., \& Teixeira, M. F. S. (2011). Crescimento micelial de Ganoderma lucidum (Curt.: Fr.) P. Karst. em resíduos lignocelulósicos disponíveis na Amazônia. Caderno de Pesquisa, 23(3), 16-25.

Machado, A. R. G., Teixeira, M. F. S., Kirsch, L. S., Campelo, M. C. L., \& Oliveira, I. M. A. (2016). Nutritional value and proteases of Lentinus citrinus produced by solid state fermentation of lignocellulosic waste from tropical region. Saudi Journal of Biological Sciences, 23(5), 621-627.

Machado, A. R.G., Martim, S. R., Alecrim, M.M., \& Teixeira, M. F. S. (2017). Production and characterization of proteases from edible mushrooms cultivated on Amazonic tubers. African Journal of Biotechnology, 16(46), 2160-2166.

Madhusankha, G. D. M. P., \& Thilakarathna, R.C.N. (2021). Meat tenderization mechanism and the impact of plant exogenous proteases: A review. Arabian Journal of Chemistry, 14(2), 2-18. 
Research, Society and Development, v. 10, n. 3, e35310313393, 2021

(CC BY 4.0) | ISSN 2525-3409 | DOI: http://dx.doi.org/10.33448/rsd-v10i3.13393

Magalhães, A. A. S., Silva, T. A., Teixeira, M. F.S., Cruz, R. F., Filho, Silva, S. D., Gomes, D. M. D., \& Pereira, J. O. (2019). Produção e caracterização de enzimas proteolíticas de Lentinus crinitus (L.) Fr. 1825 DPUA 1693 do bioma amazônico (Polyporaceae). Boletim Museu Paraense Emílio Goeldi, 14(3), 453461.

Martim, S. R., Silva, L. S. C., Alecrim, M. M., Souza, B. C., Oliveira, I. M. A., \& Teixeira, M. F. S. (2017). Proteases ácidas de cogumelo comestível da Amazônia para aplicabilidade industrial. Boletim Museu Paraense Emílio Goeldi, 12(3), 353-362.

Minitab, 2017. Minitab statistical software. LEAD Technologies, Inc. Version 18.1.

Neves, K. C. S. Produção de proteases coagulantes por espécies de Pleurotus em resíduos vegetais da Amazônia. 2014. 99f. Tese (Doutorado em Biotecnologia) - Universidade Federal Rural de Pernambuco, 2014.

Palheta, R. A., Vieira, J. N., Neves, K. C. S., \& Teixeira, M. F. S. (2011). Crescimento micelial vertical de duas espécies de Pleurotus em resíduo agroindustrial da Amazônia utilizando planejamento fatorial. Caderno de Pesquisa, 23(3), 52-60.

Ravindran, R., Hassan, S.S., Williams, G. A., \& Jaiswal, A. K, A. (2018) Review on bioconversion of agro-industrial wastes to industrially important enzymes. Bioengineering, 5(4), 2-20.

Rohan (2021). Proteases Market worth 2.21 Billion USD by 2021. https://www.marketsandmarkets.com/PressReleases/proteases.asp

Siala, R., Frikha, F., Mhamdi, S., Nasri, M., \& Kamoun, A. S. (2012). Optimization of Acid Protease Production by Aspergillus niger I1 on Shrimp Peptone Using Statistical Experimental Design. The Scientific World Journal.

Souza, R. A. T., Fonseca, T. R. B., Kirsch, L. S., Silva, L. S. C., Alecrim, M. M., Cruz, R. F., Filho, \& Teixeira, M. F. S. (2016). Nutritional composition of bioproducts generated from semi-solid fermentation of pineapple peel by edible mushrooms. African Journal of Biotechnology, 15(12), 451-457.

Tavano, O. L., Berenguer-Murcia, A., Secundo, F., \& Fernandez-Lafuente, R. (2018). Biotechnological applications of proteases in food technology. Comprehensive Reviews in Food Science and Food Safety, 17, 412-436.

Verduzco-Oliva, R., \& Gutierrez-Uribe, J. A. (2020). Beyond enzyme production: solid state fermentation (SSF) as an alternative approach to produce antioxidant polysaccharides. Sustainability, 12(2), 2-14.

Zhao, A., Li, Y., Leng, C., Wang, P., \& Li, Y. (2013). Inhibitory effect of protease inhibitors on larval midgut protease activities and the performance of Plutella xylostella (Lepidoptera: Plutellidae). Frontiers in Physiology, 9, 1-9. 